\title{
Impact of the Establishment of E-Commerce on Export Performance of Companies in Guilan Province
}

Seyed Salar Alavinasab

M.A of Business Administration (International), Rasht Branch, Islamic Azad University, Rasht, Guilan, Iran

Mohammad Taleghani ${ }^{*}$

Associate Professor, Department of Industrial Management, Rasht branch, Islamic Azad University, Rasht, Guilan, Iran ${ }^{*}$ Corresponding Author: M.Taleghani454@yahoo.com

\author{
Doi:10.5901/mjss.2016.v7n2s1p526
}

\begin{abstract}
Export development in all countries is as an economic strategy that leads to balance its relative share of the world population and its relative share of global trade. Today, e-commerce and solutions of e-business has led to facilitate and expedite the export process. Effective use of the Internet is a low-cost way to enter the international markets for companies that intend to enter the field of export. The research method was descriptive survey and questionnaire that its questions were adjusted to fit the variables discussed in this study. The statistical population included export companies in Guilan Province in 1393, of which there are over 17 companies.As the number of people who make up society is limited, research sample size on the basis of Cochran formula is at least 133.To analyze the data, SPSS, and Pearson correlation and linear regression analysis simple methods was used in order to determine the relationship between variables and the effect of the independent variable on the dependent variable. The results of correlation analysis showed a positive impact of e-commerce effective factors (managerial, organizational, cost, technological, cultural, environmental, market) on Export performance of firms. The regression analysis showed that among the seven predictor variable, variables of management, market, organizational, environmental, technological, cultural and cost are the best predictors of export performance
\end{abstract}

Keywords: E-Commerce, Export Performance, Export Companies of Guilan.

\section{Introduction}

Increasing trade, the globalization of products and services as well as international companies emphasized the continuous importance of performance of exporting companies (Rose \&shoham, 2002: 217).today, the presence on the global market by resorting to successful and efficient practices that depicts the view of the countries' economy's ability, is including necessity of adapting to the current international system in terms of its progress in the economy and industries. Of course, the use of IT is one of the necessary rings to enhance business performance in the economy of organizations andthe use of modern methods of trade as e-commerce and paperless is for facilitate trade that one of the important features of e-commerce, is lubrication methods and activities, thus reducing the cost of business(Salehi, 2013: 1776).E-commerce provides unprecedented opportunities for both developing and developed countries (Terzi, 2011).

To succeed in the world of electronics and e-commerce first and most important step, is planning to identify barriers to using e-commerce.Organizations to design and implement appropriate e-commerce strategies need to be aware of the barriers to using e-commerce.In Iran, the use of e-commerce in its preliminary stages and mainly as a promotional tool is considered.Different companies must to identify related barriers for going beyond this stage and uptake multiple benefits of e-commerce (AlamdariMeibodi\& et al, 2010:120-121).In this regard, companies in the Iran to achieve the global growth in the field of e-commerce must have strategy for the establishment of e-commerce. The establishment of e-commerce is a series of factors that in any company or organization have a different importance (BamdadSoufi\& et al, 2011: 69).

E-commerce as one of the most important tools provides greatly indicators such as increasing efficiency Increase business efficiency, liberalization, transparency of information and the development of science, culture, business at the international level to achieve a competitive advantage and increase exports for countries. These tools actually provide a large advantage in the advanced countries. Specific strategies have been proposed for developing the country because Iran's economy suffers from several problems; including strategies for export jumps for balancing between the relative 
share of the world's population and its relative share of global trade and e-commerce is one of the tools in this context that can help countries and companies. According to the above mentioned, e-commerce should be seen as a serious issue in the country and companies (Hashemi, 2010: 174). Investment is a key variable which has an interactive relationship with many economic variables like industry growth. Governments provide conditions for attraction and direction of investment via appropriate incentives. Governments approve regulations for supporting investors. Managers must have special features and competencies and long experiences and socio-communicational skills. We must start from targets in order to have effective management and managers must rely firstly on their resources and especially workforce (Rahnama et al., 2011).

Given the importance of e-commerce and realize the benefits of its application by the authorities, present study wants to measure the role of the affecting factors on the establishment and application of e-commerce on export performance in companies of Gilan province.

\section{Literature Review}

E-commerce has defined as sales through the Internet (KhodadadHoseini\& et al, 2009). E-commerce is a process that provide sell or buy goods and services using methods designed via computer networks (Yapar, Bayrakdar, \&Yapar, 2015). A wide range of factors that can affect the successful implementation of e-commerce can be seen in the literature. For example, in a study in Korea factors affecting the deployment of e-commerce were divided into four main factors institutional factors, market factors, environmental factors and technology factors. In another study in Jordan under the heading "Factors Affecting Adoption of e-commerce" in SMES, effective factors have divided in the external environment factors, organizational factors and technology factors. According to Lefboreh and colleagues (1991) four categories of the following factors are effective in the use of electronic commerce: characteristics of the company, competitiveness and strategies of enterprise management, the effectiveness of internal and external departments of organization in decidesmaking to applying technology features. Rashid and Karim have divided the factors influencing the use of e-commerce on organizational factors, technology factors, personal factors and environmental factor.

After reviewing existing related research and identify appropriate variables must be established the network of relationships between variables, so that related hypotheses will create and then test. Therefore the conceptual model of research is as follows:

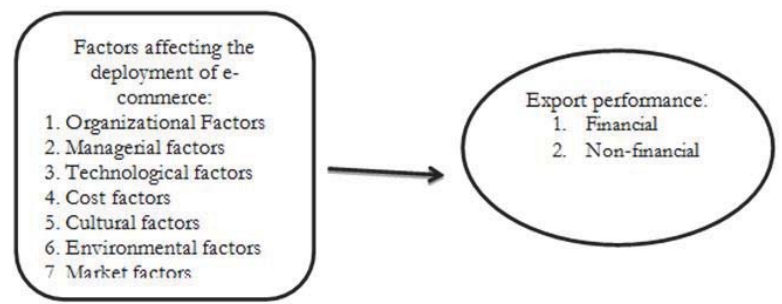

Figure 1: TheConceptual Model (Mohammadi far, 2011; Nataghi\&Nasrabadi, 2014)

\subsection{Export performance}

Export performance of the company, the degree or measure that a company has achieved its export goals, that these measures include sales, profits from exports, sales growth and entry into new market (A.k.shamsuddoha, 2006, P.93).Walker and Robert (1987) suggested that the relationship and the importance of performance dimensions among various stakeholders (investors, employees, customers) is differentAnd depends to focus on short-term or long-term period. Researchers have highlighted three main dimensions of performance. First, it is the effectiveness in the field of product and business plans for the competitors. Markers such as sales growth could demonstrate effectiveness. The second dimension is efficiency that focuses on business output rather than its input. Profitability is a key indicator that shows the dimension. The third dimension is the ability to adapt. This means that how businesses respond to changing conditions and opportunities in the environment.Export marketing literature review showed that the export performance studying is divided on the two major types:Exporters and non-exporters. The most common financial measures include: the level of export sales, export intensity and profitability of exports. Multiple measures are more preferred because 
providing more complete picture of performance and show different aspects of the performance that each of these aspects may be influenced by the specific characteristics of the firm (Moshbeki\&Khademi, 2012: 100-101). Marketing scholars and practitioners can interpret these results as helping to justify expenditures on brand and customer related marketing activities that create such long-term brand relationships with their consumers. (Taleghani et al., 2011)

\subsection{E-commerce}

Ecommerce is a business that is guided through electronic means and may contain a range of produce and information services to sell or buy products. Business tools generally include internet and global communication networks (Kulatunga, 2008, p.28).

- Organizational factors: Organizational factors in Ecommerce research defined as organizational readiness.Organizational factors that affect the establishment of e-commerce in this study are as follows: an appropriate structure for the information technology, the multiplicity of centers of decision-making, coordination between different parts of organization, the appropriateness of current practices and the impact of excessive moving of managers (Mohammadifar, 2011, P.9).

- Management factors:These factors related to management policies and their good choice in the implementation of operational projects at different times. These factors ultimately implemented from senior executives to operational managers.Management factors that affect the establishment of e-commerce in this study are: transparency in policy-making, strategic management and long-term planning and management commitment, management approach in the field of risk and risk cost and IT management (Mohammadifar, 2011, P.10).

- Technological factors:The factors that finally is related to engineering components that the factors that are a subset of manufacturing techniques and that is why they are in the group of factors such as the hardware and software applications. As well as aspects related to telecommunications infrastructure, encompasses extensive software and hardware facilities, security in telecommunications networks, experts' technical knowledge, customers' awareness of the e-commerce on establishment of the e-commerce on industry (Mohammadifar, 2011, P.10).

- Cost factors: These agents are the various costs needed to implement and improve e-commerce and these factors play a decisive role in the development and integration of Ecommerce with respect to costs. Factors such as the cost of investment in the field of telecommunications, the cost of developing and updating, and the cost of designing and connect to the Web, are among the cost factors of establishment of e-commerce that is examined in this study (Mohammadifar, 2011, P.11).

- Environmental factors:environmental factors divided into two parts :Direct and indirect ,Direct environmental factors is including business, competition, physical distribution units and customers and indirect environmental factors is including economic, social and cultural, political, legal and demographic(Mohammadifar, 2011, P.11).

- Market factors:market factors on the establishment of e-commerce that examine in this study, include: the number of competitors in the industry, quickly imitated by competitors of new goods and services, the speed of reaction of competitors to the company strategies and activities, trying competitors for increase its market share, the use of new technologies by competitors, the volume of customer feedback, customer loyalty(Mohammadifar, 2011, P.11).

\section{Previous Research}

Gregory and et al (2007) conducted the research as stimulus effects of e-commerce on export marketing strategy.This study identified the basic dimensions of e-commerceand available export marketing theory expanded through combining e-commerce stimulus with strategy-environment relationship.Stimulus of internal and external e-commerce as a foreground of export marketing strategy and also intermediaries of the relationship between environmental factors and export marketing strategy were placed conceptualization and theoretical argument. The empirical the results of research support the theory of developed export marketing strategy and prove thatwith focusing on Stimulus effects of on export marketing strategy, exporters can understand better how to use e-commerce to increase their export performance of a company.

Javalgi and Ramsey (2001) in his study entitled "Strategic issues of electronic commerce", have been studied factors affecting the growth of e-commerce.E-commerce was one of the wide applications Internet and its growth 
depends on infrastructure such as information and communications technology, social, and cultural, business and legal and governmental. The lack of any of this infrastructure can be considered an important obstacle in the implementation of e-commerce.The above infrastructures are essential to support the growth of e-commerce and utilizing of e-business strategic interests.

Nasrabadi and Nateghi (2014) did Research entitled the effects of e-commerce on development export of rose water and essential oil.This study aims to identify structural barriers of exports rose water and essential oil to the United Arab Emirates.The populationis consisted 77 persons of administrators of export companies in Kashan.Questionnaire is a kind of self-made.This study also attempts to identify the barriers to e-commerce in export of rose water extract and essential oil with using a five-point Likert scale as an indicator.There are three factors associated with the proposed model.Barriers to e-commerce export of rose water and export of rose water was determined in the following order of priority: 1- Problems and obstacles related to information infrastructure, 2- problems related to Legal, Legal problems related to, legal and security infrastructure, of infrastructure,3- Educational problems, behavioral and cultural infrastructure.

Hashemi (2010) did research entitled effect of e-commerce on the export of oil, gas and petrochemical. In this research were studied the effect of the application of e-commerce on the export of products, oil, gas and petrochemical industries and are presented conclusions and recommendations. In the study by reviewing research literature is discussed to explain the subject matter and methodology. For conducting this research used a field method that is supported by the library.The sample consisted member firms of Exporters Association products of oil, gas and petrochemicals.According to the results of research to active public policymakers in the field of export and also active managers in export recommended thatFurther to the e-commerce to develop exporting, have the necessary attention its export policy formulation.

Babagoli and et al (2009) in a study entitled "Challenges and strategies for development of e-commerce in Iran",discussedabout the requirements of e-commerce, barriers and it's extend in Iran and the establishment of ecommerce in the country are known to cause the gap between rich and poor and have emphasized on the necessity of quickly providing the technological platform in order to prevent serious damage to the economic, cultural and political structure of society.As well as because of political problems and economic sanctions have considered the necessity of making culture and providing internal context for the development of e-commerce in the inside of country.

\section{Research Hypothesis}

The main hypothesis of the research: the establishment of Ecommerce has an impact on export performance of companies.

1- The organizational factors of E-commerce have an impact on export performance of companies.

2- The management factors of E-commerce have an impact on export performance of companies.

3- The technological factors of E-commerce have an impact on export performance of companies.

4- The cost factors of E-commerce have an impact on export performance of companies.

5- The cultural factors of E-commerce have an impact on export performance of companies.

6- The environmental factors of E-commerce have an impact on export performance of companies.

7- The market factors of E-commerce have an impact on export performance of companies.

\section{Research Methodology}

Since the purpose of the research is the development of practical knowledge in the field of e-commerce development and these help managers to reach deeper insight when they are improving export performance, the present study in terms of purpose is functional.Also this study in terms of nature and methods of data collection is descriptive and causal.In this research, library study and field (through a questionnaire) method were used for data collection. In this study, to analyze the data from the questionnaire, descriptive statistics such as frequency, percentage and histogram are usedand each variable is described in the tables and indices.Then, on the inferential statistics, to assess and explain the relationship between independent and dependent variables and generalization of the results of the sample to population, Regression analysis method and test the relevant coefficients will be used by SPSS software.

The study population consisted of managers and employees of export companies in Gilan somehow are linked to the concepts of Ecommerce in 1393 of which there are over 17 companies.After the survey, total population of 203 was estimated.In this study, the sample size is calculated using the Cochranformula and questionnaires are randomly distributed among the sample. 
Cochran test statistic is calculated using the following equation:

$N=\frac{N\left(Z_{a / 2}\right)^{2} p_{q}}{(N-1) D^{2}+P Q\left(Z_{a / 2}\right)^{2}}=\frac{203 \times(1.96)^{2} \times 0.25}{202 \times(0.05)^{2}+0.25 \times(1.96)^{2}}=133$

\section{Statistical Analysis and Hypothesis Testing}

\subsection{Descriptive analysis of research data}

Table 1. Descriptive statistics for variables

\begin{tabular}{lcccccc}
\hline Variable & Number & Minimum & Maximum & Average & Standard deviation & Variance \\
\hline Organizational factors & 141 & 2 & 5 & 4.22 & .521 & .271 \\
Management factors & 141 & 3 & 5 & 4.30 & .356 & .127 \\
Technological factors & 141 & 2 & 5 & 4.17 & .346 & .120 \\
Cost factors & 141 & 2 & 5 & 3.89 & .510 & .260 \\
Cultural factors & 141 & 2 & 5 & 3.18 & .363 & .132 \\
Environmental factors & 141 & 3 & 5 & 3.80 & .382 & .146 \\
Market factors & & 2 & 4 & 3.069 & .307 & .094 \\
Export performance & 141 & 3 & 5 & 4.22 & .416 & .173 \\
\hline
\end{tabular}

As seen in the table above average for variable of export performance is 4.22 with a standard deviation of 0.416 . Also among components of the variable of Ecommerce, the highest average, related to component of management factors with amount of 4.30 with a standard deviation of 0.356 and lowest mean, related to components of the market factorswith amount of 3.069 with a standard deviation of 0.094 .

\subsection{Deductive analysis of research data}

The main hypothesis of the research: the establishment of Ecommerce has an impact on export performance of companies.

Table 2: The correlation between the establishment of Ecommerce and export performance

\begin{tabular}{lcc}
\hline $\begin{array}{l}\text { Statistics Indicators } \\
\text { Variables }\end{array}$ & Correlation Coefficient & The Significance Level \\
\hline E-commerce & ${ }^{*} .763$ & .000 \\
\hline Export performance & & \\
\hline
\end{tabular}

According to the table, the amount of significant level is less than five hundredths.For this reason, with $95 \%$ confidence, the hypothesis is confirmed and this is a significant relationship. Also on the table can say that the correlation between establishment of Ecommerce and export performance is $763 / 0$ percentthat represents a direct and positive relationship between the two variables.

Table 3: The coefficient between the variable

\begin{tabular}{|c|c|c|c|c|c|}
\hline $\begin{array}{l}\text { Statistics Indicators } \\
\text { Variables }\end{array}$ & $\begin{array}{l}\text { Correlation } \\
\text { Coefficient }\end{array}$ & $\begin{array}{l}\text { The Coefficient of } \\
\text { Determination }\end{array}$ & $\begin{array}{l}\text { Adjusted Coefficient of } \\
\text { Determination }\end{array}$ & $\begin{array}{c}\text { The Estimated } \\
\text { Standard Deviation }\end{array}$ & $\begin{array}{c}\text { The Significance } \\
\text { Level }\end{array}$ \\
\hline $\begin{array}{l}\text { Organizational factors } \\
\text { Export performance }\end{array}$ & .413 & .171 & .165 & .380 & .000 \\
\hline $\begin{array}{l}\text { Management factors } \\
\text { Export performance }\end{array}$ & .547 & .299 & .294 & .349 & .000 \\
\hline $\begin{array}{l}\text { Technological factors } \\
\text { Export performance }\end{array}$ & .938 & .158 & .152 & .383 & .000 \\
\hline $\begin{array}{l}\text { Cost factors } \\
\text { Export performance }\end{array}$ & .251 & .063 & .56 & .404 & .000 \\
\hline $\begin{array}{l}\text { Cultural factors } \\
\text { Export performance }\end{array}$ & .326 & .106 & .100 & .394 & .000 \\
\hline Environmental factors & .402 & 162 & 156 & 382 & .000 \\
\hline
\end{tabular}




\begin{tabular}{llllll}
\hline $\begin{array}{l}\text { Export performance } \\
\text { Market factors }\end{array}$ & .531 & .282 & .277 & .353 & .000 \\
\hline Export performance & .53 & \\
\hline
\end{tabular}

Based on the results of Pearson's correlation coefficient and since the amount of sig $=0.000<0.05$ is, and then amount of test statistic in all hypotheses are placed in the $\mathrm{H} 1$ area.For this reason with $95 \%$ confidence $\mathrm{HO}$ is rejected and $\mathrm{H} 1$ hypothesis is confirmed.So sub-research hypothesis are confirmed based on the effect of factors for establishment of Ecommercesuch as organizational, managerial, technological, cost, cultural, environmental and market factors on export performance.

\section{Conclusions and Findings}

Nowadays export will be considered as a constructive role and infrastructure in the development of domestic production and employment opportunities in the community. The success of a company in export can be assessed with its export performance.Hence Pundits of export marketing believe that "the identification of determinant factors of export performance" in order to increase export performance and achieve its desired level is a critical issue for companies in today's competitive market.On the other hand Acquaintance of these companies with the capabilities and benefits of the factors affecting on e-commerce and its techniques and methods how to use them can overcome some of the problems of export and will increase the effectiveness of activities of export performance. With this reasoning using various methods of e-commerce is essential to help export developing of export companies. Therefore this study took place to assess the impact of factors affecting on the deployment of e-commerce on the performance of export companies in Gilan province.And its achievement with the results of the research of researchers such as Nasr Abadi and Nateghi (2014), Norouzi and et al (2010), Gregory and et al. (2007), Hashemi (2010), Hosseini and et al (2008) are aligned.The mentioned researchers also emphasized that the factors affecting the deployment of e-commerce have a positive impact on export performance of companies.Also in other conducted researches at inside and outside of the country are largely witnesses matching the results from this study and other studies. Thus it can be stated that the independent variables have reasonable and significant explanation effect on the dependent variable.

\section{Functional Suggestions}

- The development of infrastructure and communication network and telecommunications and computer of companies

- Use of appropriate software to create secure systems and networks

- Providing tax breaks to internet exchanges in export companies

- Providing technical and management consultations and financial support, including loans without interest for the development of e-business infrastructure by the Ministry of Industry to the applicant companies applying ecommerce

- The design of a long-term plan to change the behavioral patterns and cultural of people in the field of business because these patterns of behavior is a time consuming working and long-term and cannot be dealt sectional with it.

- Pay attention to local culture of company and political and economic and the cultural issues that is unique to Iran and providing scientific and practical strategies by the academic community which is supposed development of e-commerce according to the native model also may be effective in the development of ecommerce.

- Greater use of e-commerce applications such as electronic sales systems B2B that covers operations of ordering raw material, transportation, processing and selling.

\section{Suggestions for Future Research}

- Conducting research of mixed method to measure all qualitative and quantitative variables in the applied model in this research.

- The effect of the establishment of e-government in facilitating the implementation of e-commerce

- The role of e-commerce in facilitating customs registering of country

- Compare the performance of companies that use e-commerce with companies that do not benefit from this system. 


\section{Research Limitations}

- The absence of internal quality investigation of the influence of research variables and thus not reaching the same results in the fie

- In terms of methodology should be noted that the correlation of researchesresults and then cause and effect researches is strongly influenced by the sample. So results can vary with fluctuations in the sample.

- Another limitation of this study is the period of time to do it. Period of time in this research has been limited.

- The effect biases of some of the respondents and personal opinions that may have affected the results.

- Absence providing correct information from respondents

\section{References}

A.K. shamsuddoha and M.Yunus Ali, (2006),"Medieated effects of export programs on firm export performance "Asia pacific journal of marketing and logistics, Vol.18 No.2.

AlamdarMeibodi, M., Mirabi, V.R., \& Mohammad Gholinia, J., (2010), Barriers to using e-commerce in distribution cooperatives in Tehran "cooperation, the twenty-first year, new era, Issue 4, Pages 119-149.

Babagoli, I., \&Khanlorzadeh, F., (2010), Obstacles to the development of e-commerce in Iran, "First National Conference and the Fourth Conference on Higher Education Institute Khavaran: new technologies in science and engineering.

Bamdadsofi, J., Alishiri, B., \&Abdollahi, H., (2011), Effective factors on the deployment of e-commerce in Rolled wire company of Kerman Fountains ", Journal of Economics and Business, Volume II, Issue I, pp. 67-76.

Hashemi, M., (2010), Effect of e-commerce on the export of oil and gas, "Quarterly Journal of Business, No. 54, pp. 171-200.

Hoseini, A., Ghazizadeh, M., \&AbbasiEsfanjani, H., (2008), The Influence of email marketing on the export performance of exporters sample of the industrial sector in the years 2000- 2005(with emphasis on the Internet), bimonthly Journal of Shahed University, The fifteenth year- new era, №. 32.

Kulatunga D. (2008) "Electronic commerce strategies, generic strategies, and firm performance: A study of small and medium enterprises in Aichi", Japan. 21(1): 27-46.

Mohammadifar, F, (2011), Effective factors on the deployment of e-commerce the industrial sector "Faculty of Humanities, Islamic Azad University of Sanandaj, master's thesis.

Moshabbeki, A., \&Khademi, A., (2012), the role of export promotion programs on improving the export performance of firms ", Journal of improving the management, the sixth year, №. 3, row 17, 98-135.

Nataghi, A., \& Baghi Nasrabadi, A. (2014)"Investigating the effect of ecommerce on export development of rose water and essences" Management Science Letters $4.2343-2350$

Noroozi, A., Norouzi, A. H., \& Farsi Zadeh,H. (2010). The Impact of E-Commerce on Export Development in Developing Countries 978$1-4244-5265-1 / 10 / \$ 26.00$ ๑2010 IEEE

Rahnama, Afshin.,Mousavian, SeyedJavad., Alaei, Abbas., SalimiMaghvan,Tavakkol., (2011). "The Survey of Relationship Between Creativity of Staffs and Organizational Effectiveness" Australian Journal of Business and Management Research, Vol.1 No.6 ,pp.97-104.

Salehi, A. (2013),"Barriers and Challenges of E-Commerce in Iran",Advances in Environmental Biology, 7(8): 1776-1781, 2013.

Shoham,A. and M.Rose,G. and Kropp,F.(2005)."Market orientation and performance: a meta-analysis", Marketing Intelligence \& Planning. Vol. 23. No. 5. pp. 435-454.

Taleghani, Mohammad., Samadi Largani, Mahmood., Mousavian, Seyyed Javad. (2011). "The Investigation And Analysis Impact Of Brand Dimensions On Services Quality And Customers Satisfaction In New Enterprises Of Iran", Contemporary Marketing Review, Vol. 1(6) pp. $01-13$.

Terzi, N. (2011). The impact of e-commerce on international trade and employment. Procedia - Social and Behavioral Sciences, 24, 745753. doi:http://dx.doi.org/10.1016/j.sbspro.2011.09.010

Yapar, B. K., Bayrakdar, S., \& Yapar, M. (2015). The Role of Taxation Problems on the Development of E-Commerce. Procedia - Social and Behavioral Sciences, 195, 642-648. doi: http://dx.doi.org/10.1016/j.sbspro.2015.06.145 